\title{
Mali: Empower health workers to advocate against female genital cutting
}

Frontiers in Reproductive Health

Follow this and additional works at: https://knowledgecommons.popcouncil.org/departments_sbsr-rh

Part of the Maternal and Child Health Commons, and the Public Health Education and Promotion Commons

How does access to this work benefit you? Let us know!

\section{Recommended Citation}

"Mali: Empower health workers to advocate against female genital cutting," FRONTIERS OR Summary. Washington, DC: Population Council, 2000. 
Mali

Female Genital

Cutting

OR Summary 11

\section{Empower Health Workers to Advocate against Female Genital Cutting}

\author{
Health providers are an important potential resource in campaigns to \\ eradicate female genital cutting (FGC), but a concerted effort is needed to \\ ensure that they can become effective behavior change agents. After a \\ three-day training course, providers' knowledge about FGC increased, but \\ few of them counseled their clients about FGC.
}

\section{Background}

The various initiatives to eradicate FGC in Mali - public education campaigns and conversion of traditional excisors - over the past two decades have had little impact on this traditional practice. This study assessed the use of health personnel to combat FGC, as recommended by the World Health Organization.

Conducted in 1998 by the Association de Soutien au Développement des Activités de Population (ASDAP), a nongovernmental organization, and the Ministry of Health, the study covered 14 urban and rural health centers in Bamako and Ségou region. In the eight health centers that served as experimental sites, 59 health providers, including physicians, midwives, nurses and aides, attended a three-day training course on identifying and treating medical complications related to FGC and counseling clients about FGC. In the six centers that served as control sites, 48 providers were interviewed.

\section{Findings}

- Nine in ten health providers are opposed to FGC and are willing to play an active role in educating their clients about FGC.
- Nevertheless, some providers support the medicalization of FGC. Nine percent of the providers who had been trained and 29 percent of those in the control group stated that FGC presents no health risk if performed in hygienic conditions. Thirteen percent of the 107 providers interviewed admitted that $\mathrm{FGC}$ is being practiced at their facility. Four providers said they had performed FGC procedures.

- Training did change some providers' attitudes regarding FGC. Before training, 39 percent of providers thought that an uncut girl had loose morals; after training, 26 percent still held this belief. The proportion of providers who thought that men prefer to marry women who have been cut declined from 32 percent to 28 percent, while the proportion who thought that FGC guarantees a girl's virginity decreased from 14 percent to 9 percent.

- Providers' knowledge of FGC increased dramatically after training. Roughly three in four trained providers knew at least three immediate and long-term complications (see Figure). However, providers were uncomfortable discussing FGC with their clients and felt too rushed due to the large volume of clients during the morning clinic sessions. Group health talks were held in only two of the eight experimental 


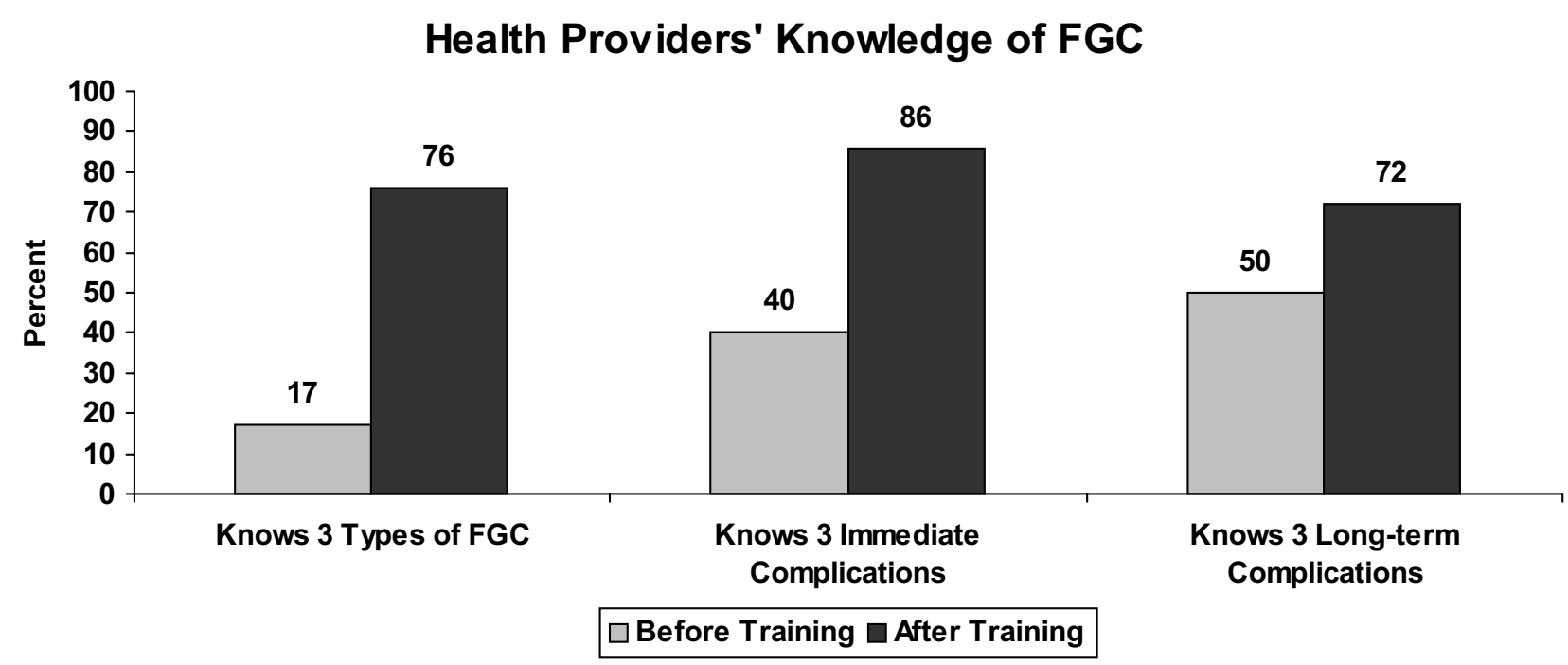

clinics. Only six of the 1,105 clients interviewed were counseled about FGC.

- The majority of health providers have provided treatment to girls with complications following FGC. More than one third had to refer a client for further treatment of FGC complications.

Nevertheless, providers acknowledged that they have limited competence in caring for FGC complications, even after training.

\section{Policy Implications}

- Mali's MOH is using the study results to develop a new curriculum to promote standardized, mandatory training on FGC for all health providers.
- Based on the study findings, the $\mathrm{MOH}$ issued a policy banning the practice of FGC in its facilities.

- The three-day training course was effective in changing provider attitudes toward FGC, but additional training in communication skills is needed to overcome providers' reticence to discuss FGC with their clients.

To eradicate FGC, community education initiatives are needed in addition to clinic education.

Diop, Nafissatou J., et al. Etude de l'Efficacité de la Formation du Personnel Socio-sanitaire dans l'Education des Client(e)s sur l'Excision au Mali. Bamako, Mali: Population Council, 1998. For more information, contact Population Council, P.O. Box 21027, Dakar, Senegal. Tel.221-824-1933; Fax 221-824-1998; E-mail: pcdakar@pcdakar.org

This project was conducted with support from the U.S. AGENCY FOR INTERNATIONAL DEVELOPMENT under Contract Number CCP3030-C-00-3008-00 and Cooperative Agreement Number HRN-A-00-98-00012-00. 